EPiC Series in Engineering
Volume 3, 2018, Pages 836-843
HIC 2018. 13th International
Conference on Hydroinformatics

\title{
AquaVar: real time models for underground and surface waters management at catchment scale
}

\author{
Philippe Gourbesville ${ }^{1}$, Marc Gaetano ${ }^{1}$, Qiang Ma ${ }^{1}$ \\ ${ }^{1}$ Polytech Lab, University Nice Sophia Antipolis, 930 route des Colles, \\ 06903 Sophia Antipolis, France \\ philippe.gourbesville@unice.fr
}

\begin{abstract}
Management of water uses requests to harmonize demands and needs which are getting more complex and sophisticated. During the past 3 decades, modeling systems for hydrology, hydraulics and water quality have been used as stand alone products and were used in order to produce an analysis of a current situation and to generate forecast according to different horizons. The current situation requests an integration of the modeling tools into the information systems that are now dedicated to the global management of urban environments. Energy distribution, water distribution, solid wastes collection, traffic optimization are today major issues for cities that are looking for functional Decisions Supports Systems (DSSs) that may operate in a sustainable perspective. The basic requirement of real time assessment of the situation, the modeling systems identified as main elements of analytics and used for forecasts have to integrate a common framework allowing modular approach and interoperability. The paper presents the interest for a generic operational approach that could be implemented in order to address the management of water uses in a complex urban environment and to provide real time assessment and forecasts. The proposed approach is illustrated with application on Var catchment $\left(3,000 \mathrm{~km}^{2}\right)$ located in the French Riviera.
\end{abstract}

Keywords: DSS, groundwater resource, information system, modeling system, real time, Var catchment.

\section{Introduction}

Management of water uses requests to harmonize demands and needs which are getting more and more complex and sophisticated especially with the growing urbanisation. Modern cities request a larger number of services for their inhabitants and expect, at the same time, to limit investments in order to constrain the tax pressure. The need of optimization appears at various levels and request the wide spread of monitoring strategies. At the same time, urban growth mobilizes last available spaces 
that are frequently under the thread of natural hazards like inundations or landslides. New urban developments appear more vulnerable and request a higher effort for risk management based on systems able to anticipate and analyse situations [1]. During the past 30 years, modelling systems for hydrology, hydraulics and water quality have been used as stand alone products and were introduced in order to produce an analysis of a current situation and to generate forecast according to different horizons. The current situation, characterized by the fast increase of monitoring devices mainly in the urban environments, requests an integration of the modelling tools into Information Systems (IS) that are now dedicated to the global management of urban environments and related services [2,3]. Energy distribution, water distribution, solid wastes collection, traffic optimization are today major issues for cities that are looking for functional Decisions Supports Systems (DSSs) that may integrated the various components and operate in a sustainable perspective. The current demand is targeting classical monitoring outputs (real time monitoring) and request forecasts based on models (analytics) and providing sufficient information for an efficient management $[3,4]$.

In addition to the analysis of the current situation by visualizing the various information sources, a frequent request is on evolution of the monitored processes in time in order to anticipate reaction and ensure an efficient management. In order to provide a real support to the decision process, several tools dedicated to the data analysis and to the simulation can be interfaced within the core part of the platform. The models used in this analytics domain start with basic statistical tools and go to complex determinist models such as those commonly used in hydroinformatics. This architecture concept for the urban information system is today commonly shared and appears as a consensus solution $[1,3]$.

\section{Nice and the Var catchment context}

The city of Nice is located on the French Riviera at the mouth of the Var catchment. The recent urban development of the fifth largest French city is currently taking place in the last available space along the Var low valley and over about $20 \mathrm{~km}$ of floodplain. Due to the complexity of challenges water supply security issues from groundwater resources, inundation risk and water resources management under the perspective of climate change - the need for a DSS has been identified since the late 90's. Unfortunately, at such time, both availability of data and technical tools (from communication protocols to modelling tools) has not permitted to engage the development of such system. However, during the last 15 years, systematic data collection on topography, climate and hydrological variables has permitted to gather a significant knowledge on the main hydrological processes within the Var catchment. Since 2014, a new approach has been engaged with the AquaVar project dedicated to the development and implementation of a first DSS able to address a wide diversity of issues: from resources management to emergency situations management [3].

\subsection{The Var catchment characteristics}

The Var catchment is located at the southeast part of France with the control area of $2800 \mathrm{~km}^{2}$ that is the largest river basin in the French Mediterranean Alps region. The elevation variation in this region is very significant and is a major characteristic of the catchment: the basin raise from $0 \mathrm{~m}$ up to $3,100 \mathrm{~m}$ above the sea level with steep slopes distributed along the branches located in the middle and upper area of the catchment. There are four main tributaries - Var, Estéron, Vésubie, Tinée - cross five main sub-catchments within the catchment (Fig.1). The climate conditions in the basin are typical for Mediterranean climate with hot dry summers and cool wet winters. The annual precipitations over the catchment are around $815 \mathrm{~mm}$, mainly concentrated in 65-80 days over the year. The surface discharge is contributed by instance rainfall, snow melting and exchange with the soil and the shallow aqua aquifer. The floods mainly appeared at the spring season with the rainfall events combined with snow melting from the high mountain area and in late autumn/early winter periods with extreme 
precipitation events covering wide areas. From the discharge records at the Napoléon III Bridge (1985-2014) located at the outlet of the catchment, the annually average discharge of the catchment is around $50 \mathrm{~m}^{3} / \mathrm{s}$ while the highest measured instantaneous discharge during flood peak can reach 3,750 $\mathrm{m}^{3} / \mathrm{s}$ like during the 1994 flood event. The Var low valley - a $22 \mathrm{~km}$ long reach - connects the mountainous area and the Mediterranean sea [5].

In the low valley, the groundwater in the unconfined alluvial aquifer is a main water resource for around 600,000 inhabitants who live in the cities and towns near the river mouth such as Nice and St Laurent du Var [6]. Groundwater is used for industrial, agricultural and domestic consumption. The annual groundwater extraction by public pumping stations (Fig.1.b) is around 50 million $\mathrm{m}^{3}$ [7]. The shallow aquifer interacts strongly not only with the river but also with the conglomerate bedrock underneath the alluvium [8].
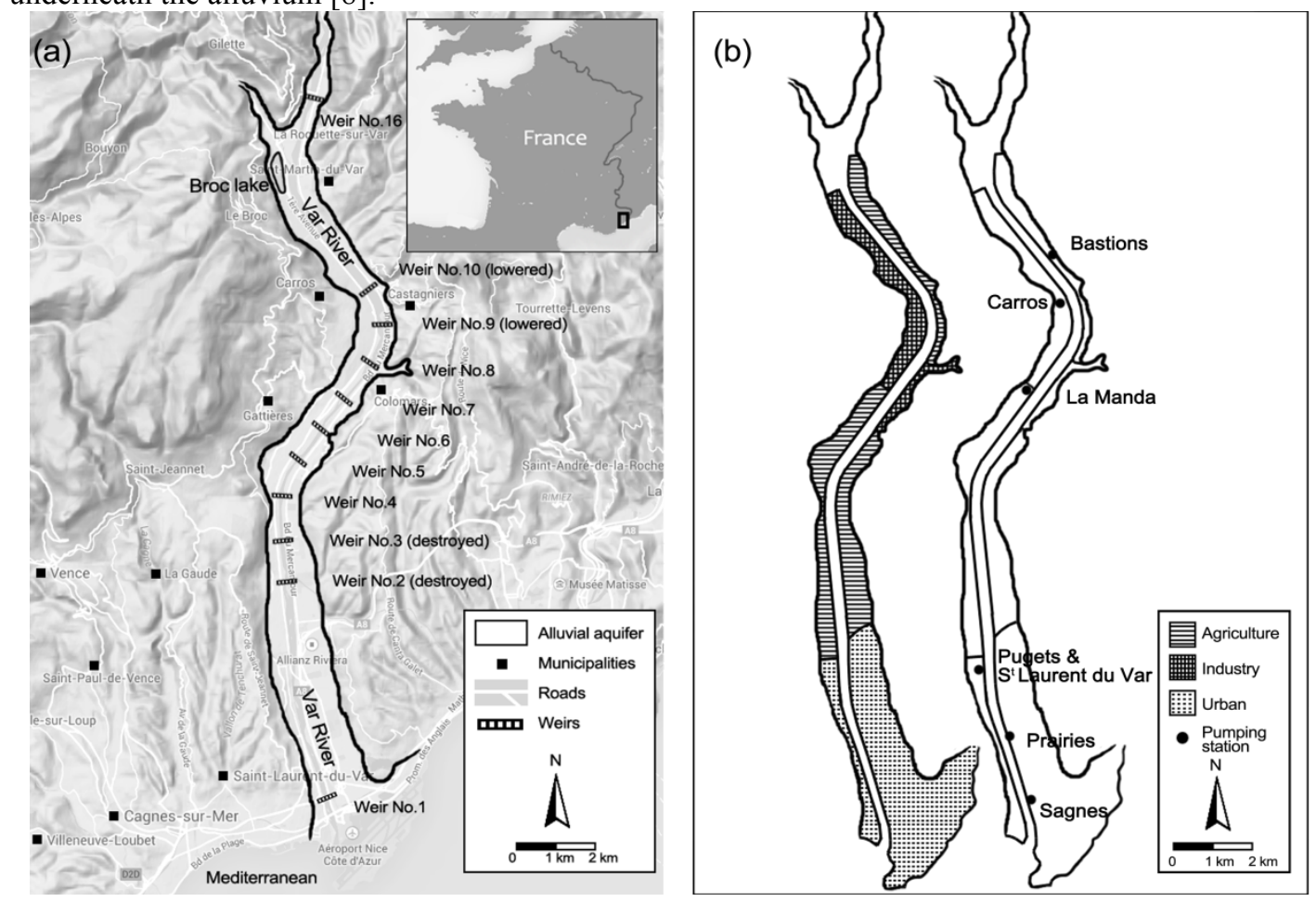

Figure 1: (a) The low Var valley; (b) Simplified land use map and pumping stations of lower Var valley.

\subsection{Challenges and expectations}

Since the beginning of the $19^{\text {th }}$ century, human activities have been changing the topography of Var river valley. Urbanization of this area has induced increasingly need for constructed area so that land has been reclaimed from river flood plain. The morphology of the river has been reshaped and artificial embankments strictly narrow the riverbed. Today, the width of riverbed varies from 150 to $280 \mathrm{~m}$ while the width of natural flood plain is from 600 to $1500 \mathrm{~m}$. This led to an increase of the water velocity thus erosions were gradually happened and observed in many places along the river. Because of the strong connection between the Var river and its aquifer, groundwater table depletion has been reported. In 1967, the most severe shortage of groundwater happened in the valley, the groundwater table was $8 \mathrm{~m}$ below its static level. In order to decrease the erosion on the riverbed so as to maintain the groundwater level, weirs were built on the riverbed since 1971. By the end of 1986, 11 
weirs were finally constructed in different cross sections of the river (Fig.1.a). The industrial zone and agricultural zone locate on the upstream area of the river while the urban area and some main pumping stations are on the downstream river mouth (Fig.3.b).

Knowing that the groundwater management in lower Var river valley faces challenges related to quantity and quality, the local water service department has an urgent demand of a physically-based hydraulic model of groundwater flow. The model should be able to consider all the important physical process of groundwater flow such as precipitation recharge, evapotranspiration, groundwater exploitation and river-aquifer exchange etc.

The Var low valley is regularly affected by serious flooding events that deeply affect the growing urban development and major infrastructure as the Nice Cote d'Azur airport $\left(2^{\text {nd }}\right.$ busiest airport in France). The different levees systems provide a structural protection for floods with a return period up to 75 years. However, the morphological dynamic of the river, increased by the different weirs, induces a quick evolution of the cross sections in several areas and may significantly reduce the protection level. This situation requests a more careful management in order to ensure a better understanding of the flooding processes and a higher security for exposed persons and goods. The solution has to provide a meaningful forecast and to be based on accurate hydraulic models.

\section{AquaVar concept}

\subsection{Global architecture}

The selected architecture for the AquaVar DSS is based on a platform elaborated over a service bus dedicated to collect and integrate field data that are related to various processes including the water services and the natural hazards. Data are formalizes through various tools such as Key Performance Indicators (KPIs), predefined alerts and directives. The synthetic dashboard allows visualizing the current situation. In addition, with the analytics components, the platform integrates deterministic modelling solutions which allow to have a full simulation of the hydrological cycle at the catchment scale, a 3D simulation of complex underground aquifer and associated relationships with $2 \mathrm{D} / 3 \mathrm{D}$ surface flow model including pollutants exchanges. The modelling system integrated within the hypervision platform is based on 3 deterministic modelling systems.

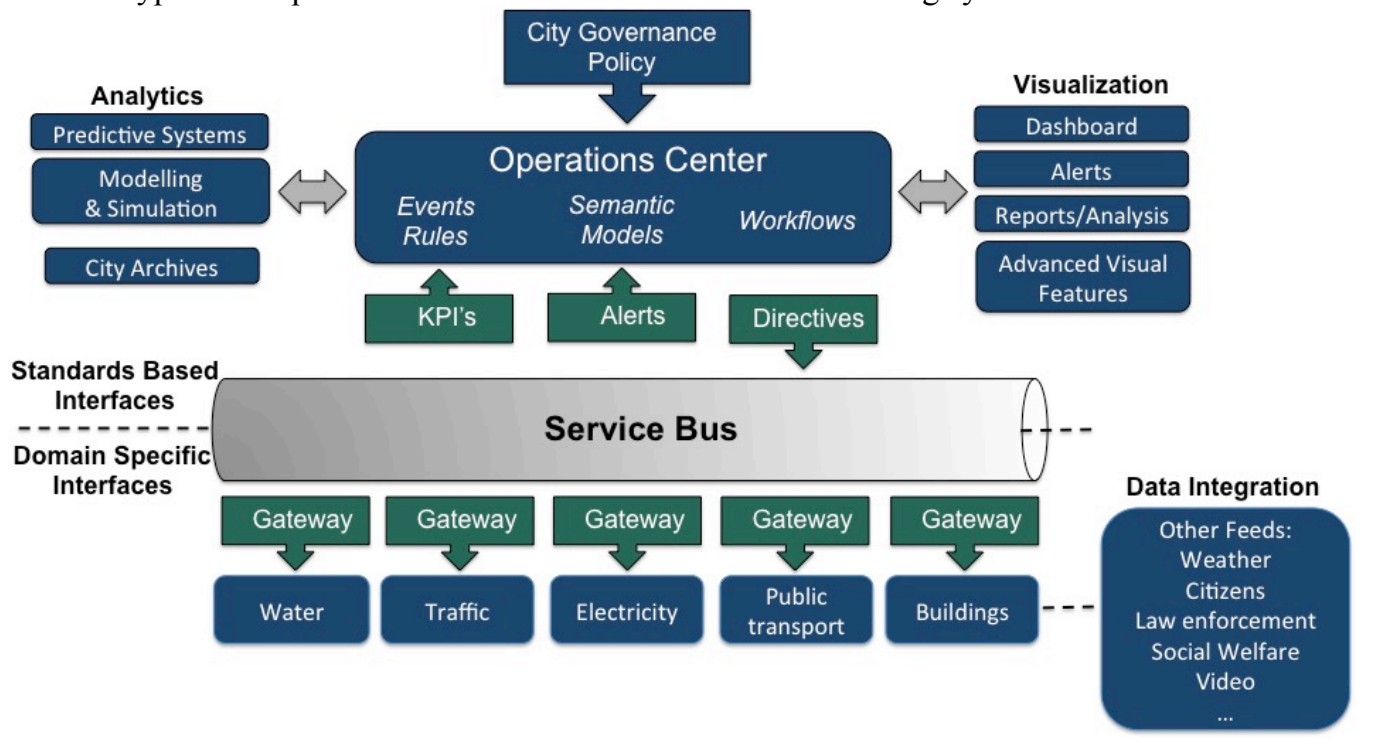

Figure 2: Global architecture of AquaVar system. 


\subsection{Implementation of models}

For the Var low valley, the demands from the local government are targeting the groundwater and flood events management. The requests are both for a real-time information on the current processes and on the possibility to assess a future situation through modelling tools. The models will integrate the Analytics domain in the global Information System (IS) architecture and will be connected through the Service Bus to the various data sources such as water levels, discharges and water quality parameters. The hypervision interface allows to display the measurements and to interact with the modelling tools that produce the simulations.

One of the key questions is obviously on the choice for the modelling tools to be integrated within the Analytics domain. In order to provide the requested diagnostics and simulations, the following modelling systems have been chosen and interconnected:

- The FEFLOW modelling system, developed by DHI, for the 3D simulation of the groundwater resources simulation. In order to represent the interactions between the river and the groundwater table, the FEFLOW model is combined with a 2D surface water model;

- The MIKE 21 system (DHI) is used as 2D surface water model and is connected with FEFLOW for the surface/groundwater interaction simulation. In addition, the system is used for flood events simulation and for the modelling of the morphological dynamic within the riverbed;

- $\quad$ The MIKE SHE system (DHI) produces the hydrological data to used as boundary conditions for FEFLOW and MIKE 21 systems.

A 3D hydraulic model has been set up (FEFLOW modelling system) over the $22 \mathrm{~km}$ of the Var low valley. The detailed geological structure has been integrated within the model in order to have an accurate representation of the processes. The validation of the model has been achieved with a simulation from September $10^{\text {th }} 2009$ to February $26^{\text {th }} 2013$. Among the 24 piezometers with automatic recorder which have been set up to monitor the daily groundwater level along the valley, 6 of them have been chosen to validate the model thanks to their fully digital recording during the simulation period. Their location enables a holistic view from the upstream to the downstream (Fig.4). The simulation results are shown with the measured data in Figure 5. The results demonstrate that the model is able to represent the dynamics of the groundwater flow by considering direct water recharge, river-aquifer exchange as well as the groundwater extraction. Consequently, the model can be used as a groundwater management tool and integrated within the hypervision platform.

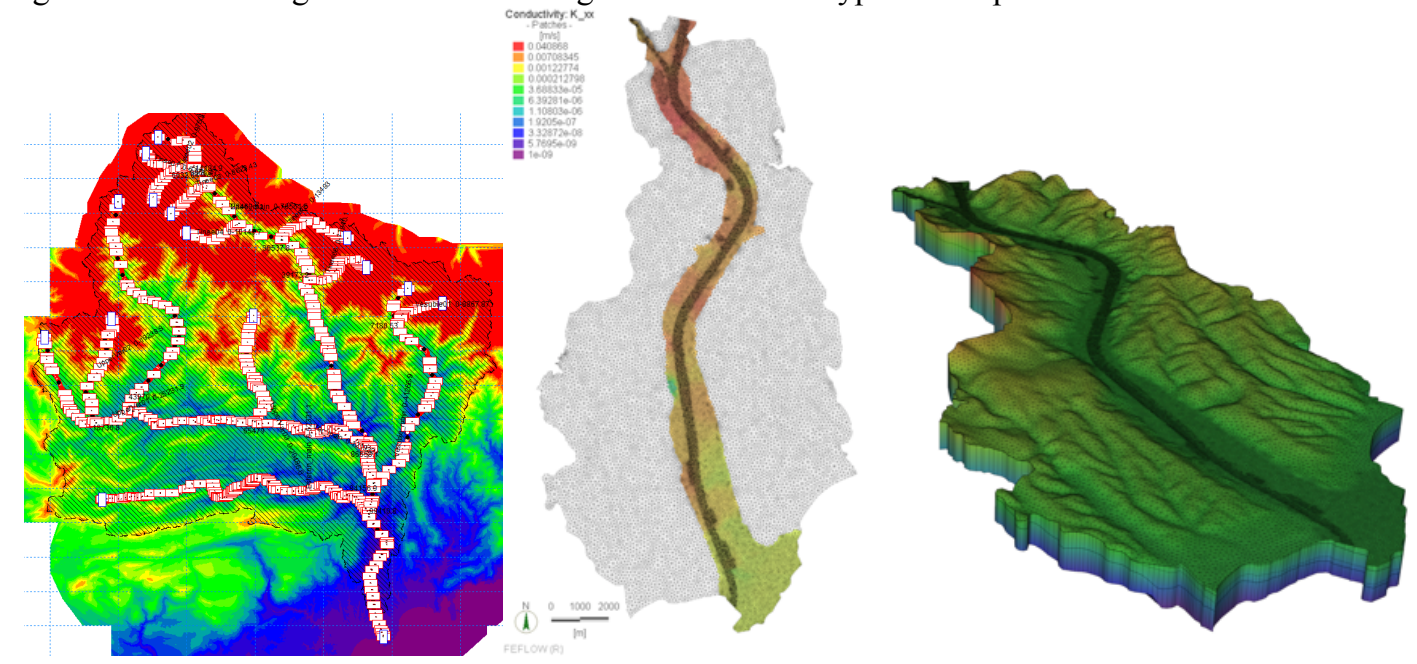

Figure 3: Mike SHE, Mike 21 and FeFlow models integrated within AquaVar DSS. 
A similar approach has been carried out with MIKE 21 FM regarding the free surface flows simulation and the morphological dynamic. The simulation of the bed evolution has been carried out with Sand Transport module in MIKE 21 FM that calculates the sediment transport capacity, the initial rates of bed level changes and the morphological changes for non-cohesive sediment due to currents. The sediment transport computation is based on hydrodynamics conditions and sediment properties. In order to obtain an efficient MIKE 21FM model, several meshes have been created to simulate the same flood event $\left(3^{\text {rd }}\right.$ October 2015 to $6^{\text {th }}$ October 2015). The built model with a $10 \mathrm{~m}$ resolution has demonstrated efficiency and well reproduced observed values. High-resolution mesh has been implemented in order to represent properly the hydraulic structures and their effects.

For the hydrological modelling, a similar approach has been implemented with MIKE SHE over the full catchment. The validation has been carried out over a period of 3 years after the validation of the numerical grid to use for the surface runoff estimation. Good results have been also obtained with this deterministic approach that provides the input data for FEFLOW and MIKE 21 systems. The 3 modelling systems are currently integrated within the AquaVar engine for the operational implementation.

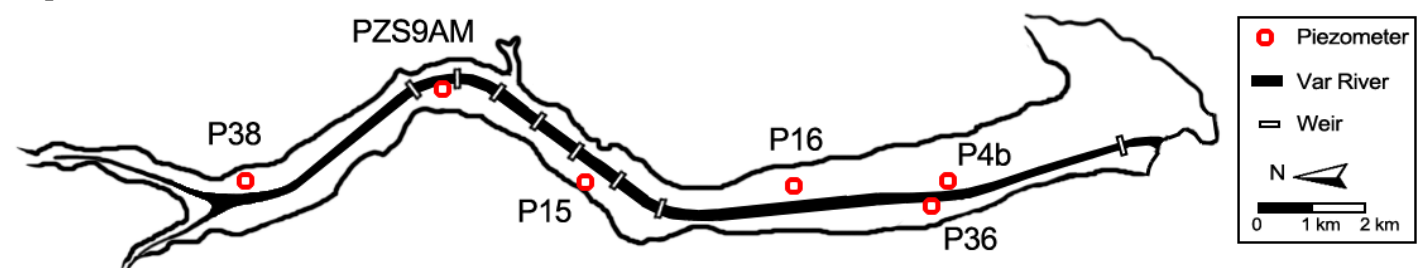

Figure 4: Piezometer used for groundwater model validation.

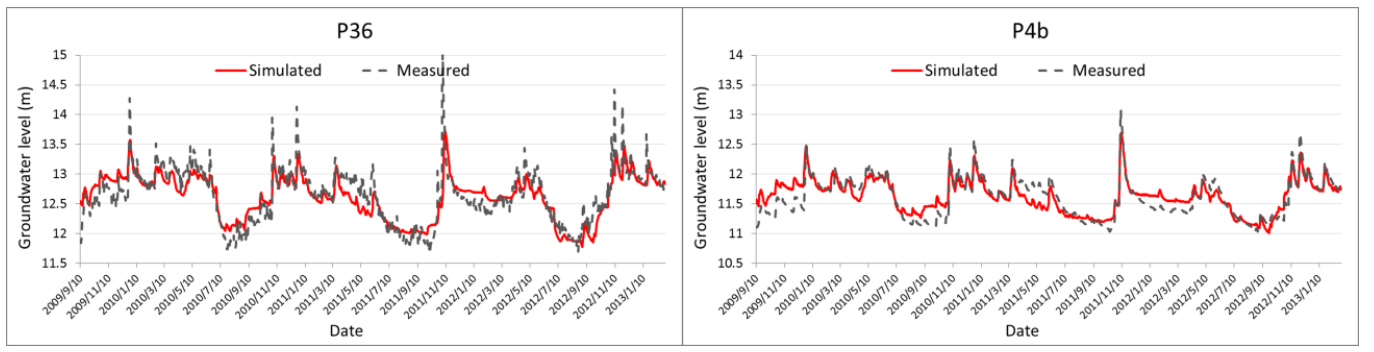

One innovative approach of the AquaVar project is the use of common modelling software as non-

Figure 5: Comparison between simulated and recorded groundwater levels.

interactive services. Modelling systems like Mike SHE, Mike 21 or Feflow are commonly used on the desktop computer as highly interactive applications where the user can take advantage of the numerous visualization features available. Conversely, in the AquaVar system, those software are used in batch mode and are viewed as modules managed by a program named the orchestrator. The AquaVar engine (Fig.6) automates the management of the modelling services by coordinating the exchange of data through their interactions.

The engine consists in the following modules:

- Simulation engines: a simulation engine is a wrapper around a specific simulation software like Mike SHE, Mike 21 or Feflow. The wrapper makes it easy to add a new simulation engine with no change in the architecture;

- Configuration modules: each simulation engine relies on a corresponding configuration module to automatically set up the simulation parameters. The configuration module is also able to perform data format conversion when necessary; 
- Scheduler: the scheduler allows to run automatically the simulation engines in the background at regular intervals. The scheduler uses a table similar to a Unix crontab which can be set up by the user;

- Data acquisition module: this module fetches the input data from a data store which itself collects live data from sensors. This module implements a common interface which allows easy connection to new data sources;

- Data delivery module: this module pushes the result files from simulation engines into a database. Similar to the previous one, this module implements a common interface which allows to deliver the results in different ways (database, plain file system, etc.)

- Orchestrator: the orchestrator manages all the other modules and can be parametrized by the user through a web-based user interface. The user can set all the simulation parameters including the time step for the simulation engines. The administrator is also able to stop or restart a simulation engine.

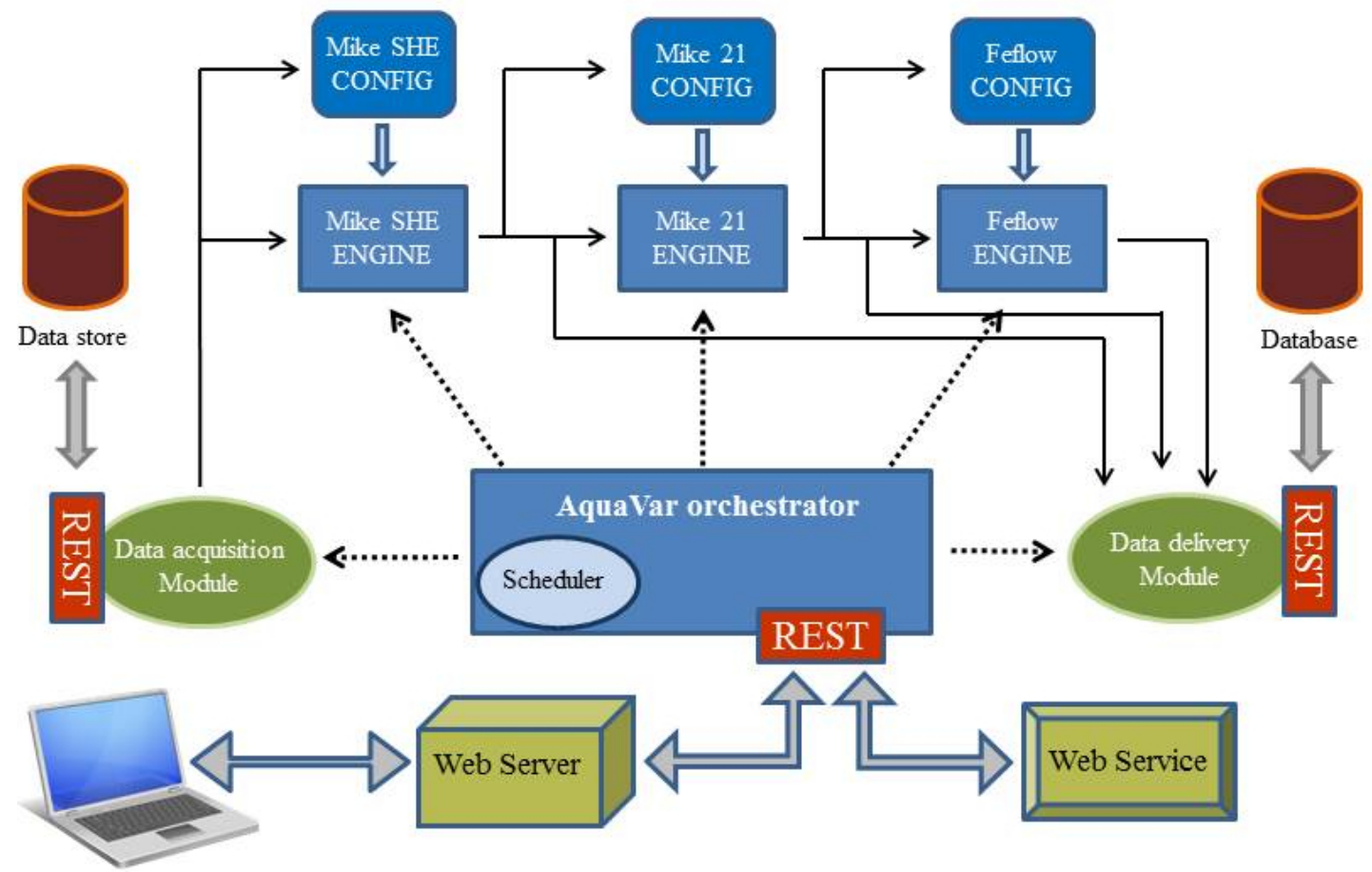

Figure 6: The AquaVar engine.

The data acquisition and data delivery modules as well as the orchestrator communicate with external applications through RESTful (Representational State Transfer) interfaces [9]. RESTful Application Program Interfaces (APIs) rely on the HTTP protocol and provide an architecture style suitable for networked applications. This architecture allows to transparently access the AquaVar engine through a web-based user interface or alternatively as a web-service. The current version of the AquaVar engine is written in Java 1.8 [10] and the RESTful APIs are powered by Jersey [11]. 


\section{Conclusions \& Perspectives}

The selected architecture for the DSS AquaVar is based on the interoperability of the various models and is integrated in a platform allowing to organize the workflows of data and the production of real time information's used by the decision makers and different stakeholders. One of the main interests of the approach is to integrate an existing hypervision platform already implemented and used for urban monitoring. The models providing a real added value for the decision process are integrated within the Analytics domain in the global Information System (IS) architecture.

The current approach has been implemented within the AquaVar project, on the Var catchment located in the French Riviera and for an area close to $3,000 \mathrm{~km}^{2}$. Obviously the developed concept for the DSS can be extended to various catchments and for various objectives such as flood management, groundwater resources management, etc. The obtained results demonstrate both the efficiency of the approach and the interest from the management point of view.

\section{Acknowledgements}

This research is currently developed within the AquaVar project with the support of Metropole Nice Côte d'Azur, Agence de l'Eau Rhone Mediterranéen, Nice Sophia Antipolis University, Conseil Départemental 06 and Meteo France. The work benefited from the data provided by the Metropole Nice Côte d'Azur, Conseil Départemental 06, Meteo France and H2EA.

\section{References}

[1] P. Gourbesville, Philippe, "ICT for water efficiency." In Environmental Monitoring. Intech, 2011.

[2] P. Gourbesville, J. Batica, J. Y. Tigli, S. Lavirotte, G. Rey, D. K. Raju. "Flood warning systems and ubiquitous computing." La Houille Blanche, 6, 2012, pp. 11-16.

[3] P. Gourbesville, M. Du, E. Zavattero, Q. Ma, M. Gaetano, Decision Support System Architecture for Real-Time Water Management. In: Gourbesville P., Cunge J., Caignaert G. (eds) Advances in Hydroinformatics. Springer Water. Springer, Singapore, 2018, pp 259-272.

[4] I. Demir, W. F. Krajewski, Towards an integrated flood information system: centralized data access, analysis, and visualization. Environmental Modelling \& Software, 50, 2013, pp 77-84.

[5] C. Potot, G. Féraud, U. Schärer, A. Barats, G. Durrieu, C. Le Poupon, Y. Travi, R; Simler, Groundwater and river baseline quality using major, trace elements, organic carbon and $\mathrm{Sr}-\mathrm{Pb}-\mathrm{O}$ isotopes in a Mediterranean catchment: The case of the Lower Var Valley (south-eastern France), Journal of Hydrology, 472, 2012, 126-147.

[6] M. Moulin, Nappe de la basse vallée du Var (Alpes-Maritimes), suivis 2006 quantité et qualité. BRGM, France, 2009.

[7] Y. Guglielmi, Hydrogéologie des aquifères Plio-Quaternaires de la basse vallée du Var, $\mathrm{PhD}$ thesis, Université d'Avignon et des Pays du Vaucluse, France, 1993.

[8] Y. Guglielmi, J. Mudry, Estimation of spatial and temporal variability of recharge fluxes to an alluvial aquifer in a fore land area by water chemistry and isotopes. Groundwater, 34 (6), 1996, pp 1017-1023.

[9] RESTful : https://en.wikipedia.org/wiki/Representational state transfer

[10] Java 1.8: http://www.oracle.com/technetwork/java/javase/overview/index.html

[11] Jersey: https://jersey.github.io/ 